\title{
Evaluation of the Psychometric Properties of the Swiss French Version of Older People's Quality Of Life Questionnaire (OPQOL-35-SF)
}

\section{Sophie Carrard ( $\nabla$ sophie.carrard@hevs.ch )}

HES-SO Valais-Wallis Haute Ecole de Sante https://orcid.org/0000-0002-3147-5848

Claudia Mooser

Institut Notre-Dame de Lourdes

Roger Hilfiker

HES-SO Valais-Wallis Haute Ecole de Sante

Anne-Gabrielle Mittaz Hager

HES-SO Valais-Wallis Haute Ecole de Sante

\section{Research}

Keywords: older people, quality of life, questionnaire, psychometric properties

Posted Date: November 9th, 2021

DOI: https://doi.org/10.21203/rs.3.rs-1030056/v1

License: (c) (i) This work is licensed under a Creative Commons Attribution 4.0 International License. Read Full License

Version of Record: A version of this preprint was published at Health and Quality of Life Outcomes on March 9th, 2022. See the published version at https://doi.org/10.1186/s12955-022-01950-w. 
Manuscript_OPQOL-35-fr_for BMC Springer Nature_20.10.21

1 Title page

2

3 Evaluation of the psychometric properties of the Swiss French version of Older People's

4 Quality Of Life questionnaire (OPQOL-35-SF)

5

6

7 Sophie Carrard, HES-SO Valais-Wallis, School of Health Sciences, Physiotherapy,

8 Rathausstrasse 25, 3954 Leukerbad (VS-Switzerland), sophie.carrard@hevs.ch

9

10

Claudia Mooser, Institut Notre-Dame de Lourdes, 3960 Sierre, (VS-Switzerland),

11 claudia.mooser@hotmail.ch

Hilfiker Roger, HES-SO Valais-Wallis, School of Health Sciences, Physiotherapy,

Rathausstrasse 25, 3954 Leukerbad (VS-Switzerland), roger.hilfiker@hevs.ch

15

Anne-Gabrielle Mittaz Hager, Caphri-Care and Public Health Research Institute and HES-SO

Valais-Wallis, School of Health Sciences, Physiotherapy, Rathaustrasse 25, 3954 Leukerbad

(VS-Switzerland), gaby.mittaz@hevs.ch

19

20

Corresponding Author:

21 Sophie Carrard, HES-SO Valais-Wallis, School of Health Sciences, Physiotherapy,

Rathausstrasse 25, 3954 Leukerbad (VS-Switzerland), sophie.carrard@hevs.ch 
Manuscript_OPQOL-35-fr_for BMC Springer Nature_20.10.21

1 Abstract (max 350 words)

2

3 Background: The proportion of older people aged more than 65 years old is continuously

4 increasing in the world population. The quality of life is an important factor in their

5 biopsychosocial handling. The questionnaire "Older People's Quality of Life-35" (OPQOL-35)

6 has been specially developed for the assessment of the senior's quality of life. The aim of this

7 study is to translate and evaluate the psychometric properties of the transcultural Swiss

8 French version of the OPQOL-35 questionnaire (OPQOL-35-SF).

9

Method: Forward-backward procedure was applied to translate the original questionnaire

11 from English into Swiss French. Then, a sample of older people completed the questionnaire.

The construct validity was evaluated by comparing the results of the OPQOL-35-SF with the

scores of three other questionnaires (WHOQOL-OLD, CASP-12 and EQ-5D-5L) and two visual analogue scales (health and quality of life). The questionnaire's structure has been assessed through exploratory and confirmatory factor analysis. The OPQOL-35-SF questionnaire was submitted a second time after 7 to 23 days to evaluate the reliability.

Results: 264 older people completed all the questionnaires once and 262 the OPQOL-35-SF a second time. The mean age of participants was $76.8(S D=7.1)$. Most of them were women $(73,9 \%) . \mathrm{KMO}$ is of 0.86 and the Bartlett's test of sphericity is significant ( $p<0.001)$. The result of EFA shows 8 factors with eigenvalues greater than one, which explained $58 \%$ of the observed variance. All the items have a significant impact $(<0.30)$ in at least one factor. The 
Manuscript_OPQOL-35-fr_for BMC Springer Nature_20.10.21

24 consistency is good with a Cronbach's alpha at 0.875 for test and at 0.902 for retest. Test-

25 retest reliability presents an $\mathrm{ICC}_{2.1}$ at 0.83 (IC 0.78 to 0.87 ).

26

27 Conclusion: The Swiss French version of the questionnaire OPQOL-35 shows psychometric

28 properties which permit its use in the clinical practice or for research purposes. A 29 supplementary sample would be necessary for a better repartition of the items in the different 30 factors.

31

32 Keyword: older people, quality of life, questionnaire, psychometric properties 
Manuscript_OPQOL-35-fr_for BMC Springer Nature_20.10.21

1

2

3

4

5

6

7

9 living at home.

\section{Background}

( 2050.(3)

As the world population is ageing faster than in the past, the World Health Assembly endorsed, in August 2020, the "Decade of healthy ageing" (2020-2030). This acceleration in ageing will have an impact on almost all aspects of the society.(1) Between 2015 and 2050, the proportion of the world's population over 60 years is expected to nearly double from $12 \%$ to $22 \%$.(2) In the European Union, people over 60 represented around 15\% in 2014 and could reach $30 \%$ by

Ageing is associated with the decline of health (4) and often related to multiple chronic and acute diseases.(5) This overloads the health care system, both in hospitals and in community care. (6) Due to the ever-increasing costs of health care, older people leave the hospital earlier than before.(7) Therefore home-based cares are increasingly required to provide assistance for daily tasks and enable older adults to age at home. $(8,9) \ln 2018,1,5 \%$ of Swiss people aged between 65 and 79 years were living in a health care institution and there were $15,3 \%$ of the over 80.(10) In the future, most of the older people, healthy or not, will live at home as long as possible. In addition to their care role, one goal for caregivers is to enhance quality of life (QoL).(11) Maintaining QoL is one of the most important outcomes of care services for older adults.(8) Measuring QoL could help to predict adverse health outcome, such as death and nursing home placement in older people, even after adjustment for frailty.(12) However, it is not evident how QoL should be defined and how it should be assessed in older people still

\section{riving at home.}


Manuscript_OPQOL-35-fr_for BMC Springer Nature_20.10.21

24

Quality of life can inherently be defined as "a dynamic, multi-level and complex concepts, reflecting objective, subjective, macro-societal, and micro-individual, positive and negative influences which interact together".(13) Quality of life is also a network of objectives and subjective factors, that includes relationships between psychological and social indicators, objectives living conditions and the subjective well-being.(14) In their recent thematic synthesis, Van Leeuwen et al. categorized and described the QoL aspects into nine domains and thirty-eight subthemes.(8)

There is a multitude of questionnaires permitting the evaluation of quality of life. Some of them have been developed specifically for older adults.(15) The most used questionnaires in this field differ in the number of dimensions analyzed as well as in the number of items. The questionnaire WHOQOL-OLD contains 24 items distributed in six dimensions.(16) The CASP questionnaires evaluate four dimensions (Control, Autonomy, Self-realization and Pleasure) standing for the acronym. It exists with 19 (CASP-19) (17) or 12 (CASP-12) items.(18) The WHOQOL-AGE, two dimensions and 30 items (19), was constructed with five items of WHOQOL-OLD and the eight items from the EUROHIS-QOL.(20) The OPQOL-35 questionnaire (21) is composed of 35 items in eight dimensions. It exists in a brief version of it with 13 items.(22)

Most of these questionnaires have been conceptualized and validated in English. Some of them have been translated into different languages. To our knowledge, the OPQOL-35 has been translated and validated to be used in Iran (23), Czech Republic (24), China (25) and Uganda (26). It was also used in several studies in Albania (27), India (28), Sri Lanka (29), Pakistan (30), Malesia (31) and Indonesia (32). Some countries, such as Turkey (33), Iran (34) 
Manuscript_OPQOL-35-fr_for BMC Springer Nature_20.10.21

48

49

50

51

52

53

54

55

56

57

58

59

60

61

62

63

64

65

66

67

68

69

and Norway (35), translated and used the OPQOL-brief with thirteen items. Although French

is spoken by about 300 millions of people in the world, making it the fifth most widely used language in the world (36), the OPQOL-35 is not yet available in French. The aim of this study was to evaluate the psychometric properties of the Swiss French version of Older People's

Quality of Life questionnaire (OPQOL-35-SF).

\section{Methods}

\section{The original version of the OPQOL questionnaire}

The OPQOL-35 was developed by Ann Bowling. $(21,37,38)$ It consists of 35 statements for which older people must select their agreement between "strongly agree", "agree", "neither agree nor disagree", "disagree", "strongly disagree" or with a score ranking from 1 to 5. Scoring needs reverse coding of positive items. Higher score represents better quality of life. The total score ranges from 35 (worst possible QoL) to 175 (best possible QoL). This questionnaire covers eight domains: a. Life overall (4 items), b. Health (4 items), c. Social relationships and participation (8 items), d. Independence, control over life and freedom (5 items), e. Home and neighborhood (4 items), f. Psychological and emotional well-being (4 items), g. Financial circumstances (4 items) and h. Culture and religion (2 items.) Psychometrics proprieties of the original English version of the OPQOL-35 were analyzed by Bowling. (21) Cronbach's alpha statistic ranged between 0.70 and 0.90 for internal consistency without item redundancy. Test-retest correlations (four weeks) ranged from moderate to high (r 0.403-0.782). Convergent construct validity was tested with CASP-19 (17) and WHOQOLOLD (16). OPQOL-35 showed moderate to high correlations (rho $0.380-0.732, p<.01$ ) for total scores. 
Manuscript_OPQOL-35-fr_for BMC Springer Nature_20.10.21

70

71

72

73

74

75

There is no consensus for the factorial structure of this questionnaire. Although the English version includes eight dimensions, principle components analysis (PCA) identify mainly two or four dimensions (21) but also nine (38). Chinese and Persian authors of the both translated versions of OPQOL-35 identified eight dimensions $(23,25)$ while Czech authors of the Czech translation estimate seven dimensions as optimal (24).

\section{The Swiss French version of the OPQOL questionnaire}

With the consent of Ms. Ann Bowling, the author of the original version, a research team translated the OPQOL-35 questionnaire into French according to the current guidelines.(39) A health professional and a naive translator translated forward the English version into Swiss French (resp. translation 1 (T1) and translation 2 (T2)). Both translators and a recording observer produced a synthesis of the translation, resulting into a first Swiss French version of the questionnaire (T-12). Two persons translated T-12 back. Both were native English speakers and not informed of the concept explored. Both back translations (BT1 and BT2), both forward translations (T1 and $\mathrm{T} 2$ ), $\mathrm{T}-12$ and the original English version of the questionnaire were submitted to an expert committee to consolidate all the versions and develop the prefinal version of the Swiss French OPQOL-35. This prefinal version was then submitted to 19 older adults which gave comments and remarks. These feedbacks were included in the second prefinal version. Bütikofer \& Rausis (40) submitted the second prefinal version to 37 older people. As no comprehension issues were pointed out, this version is effective as the final Swiss French version. 
Manuscript_OPQOL-35-fr_for BMC Springer Nature_20.10.21

93 We recruited older adults, aged 65 years or more, living in their own home and able to

94 understand and write French language in two French speaking cantons of Switzerland (Vaud 95 and Valais) during two periods: from April 2017 to May 2017 and from June 2018 to December

2018. They were recruited from medical-social centers, physiotherapy practices, associations of elderly people and personal contacts.

Recommendations for sample size for exploratory factor analysis (EFA) differs widely in the literature: from 50 to 1'000 subjects (41); or between five and ten subjects per items $(42,43)$; or more than 100 (44). Two hundred subjects seems to be necessary for a confirmatory factor analysis (42). Considering a minimum of 50 subjects (45) and between three and ten subjects pro items (23), we opted for seven to eight subjects per item, i.e. between 245 subjects and 280 subjects.

\section{Measures}

To evaluate the construct validity of the Swiss French version of the OPQOL-35, total scores have been correlated with the French versions of the Visual Analogue Scale (VAS), WHOQOLOLD (46), CASP-12 (18) and EQ-5D-5L (47). Authorizations have been received by the World Health Organization (WHO) for the use of the WHOQOL-OLD and by EuroQol for the EQ-5D5L. CASP-12 was free of use.

VASs are single-item self-reported measurement tools. They are often used in health care practice to assess pain (48), patient satisfaction (49), anxiety (50) and health related quality of life (51). The scientific literature does not permit us to attribute one or more authors to it, but it seems to have been developed and then used empirically by physicians and caregivers.(52) VAS global quality of life shows a good validity and an excellent reliability. It is recommended 
Manuscript_OPQOL-35-fr_for BMC Springer Nature_20.10.21

117

118

119

120

121

122

123

124

125

to measure global quality of life in clinical trials.(53) It was represented by a horizontal line of 100-mm ranging from 0 "worst imaginable quality of life" to 100 "perfect quality of life".

The WHOQOL-OLD was developed from WHOQOL-100, which is a questionnaire of the WHOQoL Group within the World Health Organization.(16) It measures QoL with 24 items in seven subscales: sensory abilities; autonomy; past, present and future activities; social participation; death and dying; and intimacy (four items per subscale). Items are scored with reverse coding of positive responses, so that higher score means higher QoL between 24 (lowest possible QoL) to 120 (highest possible QoL). Response scales are all 5-point but vary in their wording ("Not at all" to "An extreme amount" / "Completely" / "Extremely"; "Very poor" to "Very good"; "Very dissatisfied" to "Very satisfied"; "Very unhappy" to "Very happy").

CASP questionnaires were developed on the theories of Maslow and Giddens about the satisfaction of the human needs.(17) Quality of life is evaluated in four domains: control, autonomy, self-realization, and pleasure. The original version contains 19 items and two short versions with twelve items have been developed: one in 2005 , specifically for the Survey of Health, Aging and retirement in Europe (54) and a second one in 2008 (55). Items are scored on a 4-point Likert response scale "Often", "Sometimes", "Not often" and "Never", with reverse coding of positive responses, so that higher scores mean higher QoL. The scale of the CASP-12 ranges from 0 (complete absence of QoL) to 36 (total satisfaction in all four domains).

EuroQol Group developed in the 90's the EQ-5D to evaluate the quality of life related to health. Later the questionnaire was added three levels (3L) and in 2009, EuroQol Group introduced five levels (5L) to improve the instrument's sensitivity and to reduce the ceiling effects. The 
Manuscript_OPQOL-35-fr_for BMC Springer Nature_20.10.21

141 tool consists of two parts: one for the descriptive system and the second for the visual

142 analogue scale (EQ VAS). The descriptive system comprises five dimensions: mobility, self-care,

143 usual activities, pain/discomfort, and anxiety/depression. Each dimension has five levels: "no

144 problems", "slight problems", "moderate problems", "severe problems" and "extreme

145 problems". The EQ VAS records the patient's self-rated health on a vertical visual analogue

146 scale, where the Endpoints are labelled "The best health you can imagine" and "The worst

147 health you can imagine".(56) Scoring is calculated with an algorithm specific to each country.

149 Data collection

150 The questionnaires were self-administrated under the supervision of a research assistant (SC

151 or $\mathrm{CM}$ ), sometimes individually and sometimes in group. There were completed on electronic

152 tablets, laptops or in paper format, at the subjects' homes or in another location of their

153 convenience. To analyze the test-retest reliability, the OPQOL-35-SF was administrated twice

154 within a time interval of 6 to 23 days. There is no significant difference, clinical or statistical,

155 with an interval of two days or two weeks between two administrations.(57) In some

156 exceptional situations, and for logistical reasons, the questionnaire for the retest was handed

157 out at the end of the first meeting with a pre-stamped and pre-addressed envelope.

158 Instructions were to complete the questionnaire in seven days and send it back.

159 During the first meeting, the research assistant explained in detail the course of the study. The

160 participants completed, in this order, their personal data and general information about

161 health status, the questionnaires WHOQOL-OLD, CASP-12, EQ-5D-5L and OPQOL-35-SF. The

162 first meeting lasted between 30 minutes (individual meeting) and two hours (group meeting).

163 During the second meeting, the participants completed only the OPQOL-35-SF and answered

164 to the question: "Since our first meeting, have you experienced any events that could have 
Manuscript_OPQOL-35-fr_for BMC Springer Nature_20.10.21

165

166

167

168

169

170

171

172

173

174

175

176

177

178

179

180

181

182

183

184

185

186

187

188

influenced your quality of life?". If the answer was "Yes", it was asked: "Does this event influence your quality of life positively or negatively?" and the participant was asked to describe this event. The second meeting lasted between 10 and 30 minutes.

Data have been collected online on the software REDCap (Research Electronic Data Capture) (58) and have been saved on a secure server in the University of Applied Sciences in Fribourg. All data have been exported in EXCEL to be cleaned before analysis with the software R, version 3.5.2 (within R-Studio), and Stata version 15.1.

\section{Data analysis}

Construct validity: The factor structure of the OPQOL-35-SF was evaluated by performing EFA with varimax rotation.(59) It permits to group the variables by factors and eliminate those that are not related to the construct. $(44,60)$ In brief, it permits to measure the coefficient of variance of items between two populations. A large variance shows a difference in the meaning of the question which may be due either to the translation or to cultural variation.(61) Factor analysis could be exploratory or confirmatory; both could be complementary.(44) For factor analysis, the Kaiser-Meyer-Olkin Measure of Sampling Adequacy (KMO) should exceed the threshold of $0.8(62,63)$ and the correlation matrix must contain correlations $=0(p<0.05)$ with the Bartlett's Test of Sphericity $(41,64)$. EFA permits the identification of the different factors that define the construct.(60) There is no expectation as to the nature and number of factors and this helps to purify questionnaires by grouping intercorrelated questions. $(41,42,44)$ It is measured using Principal Component Analysis (PCA) and Varimax rotation. It is expressed by eigenvalues $>1.0$ and variance coefficients $>0.40$ from the correlation matrix. $(23,25,42)$ The weight of the variables represents the correlation between 
Manuscript_OPQOL-35-fr_for BMC Springer Nature_20.10.21

189

190

191

192

193

194

195

196

197

198

199

200

201

202

203

204

205

206

207

208

209

210

211

the original variable and the factor. The weight should be greater than 0.35 for a sample of 250 to 350 individuals. Our analysis is based on a threshold of 0.30 , as in the study by Bowling et al.(38) Scree plots permit the identification of the ideal number of factors, either the one before the inflection point of the curve, or the one at the level of the ideal eigenvalue, equal to 1.(64)

Convergence validity was evaluated using Spearman's rank correlations between scores of VAS for QoL, the OPQOL-35-SF, WHOQOL-OLD, CASP-12 and EQ-5D-5L, including its VAS for health.(65) Because the scoring scales of these questionnaires aren't similar, they all were converted on the scale used for the OPQOL-35 (Additional material I) for the analysis.

Cronbach's alpha tests the strength of the association between each scale item and the full scale. It was used to evaluate the internal consistency.(65) The closer the Cronbach alpha is to 1 , the more reliable it is. It should be between 0.7 and $0.9 .(21,45,66)$

Intra-class correlation coefficient, two-way random effects, absolute agreement, single rater (ICC 2.1 ) has been used for the test-retest reliability.(67) Terwee et al. (45) and De Vet et al.(61) consider an ICC of 0.70 as acceptable to demonstrate good reliability. Koo and Li (68) suggest that ICC values less than 0.5 are indicative of poor reliability, values between 0.5 and 0.75 indicate moderate reliability, values between 0.75 and 0.9 indicate good reliability, and values greater than 0.90 indicate excellent reliability. Agreement was analyzed in percentage, with weighted Cohen's kappa coefficient and with prevalence-adjusted bias-adjusted kappa (PABAK). The use of PABAK minimizes the influence of a response difference of 1 , as the responses to the items range from 1 to $5 .(69,70)$ Landis and Koch consider a score $>0.80$ as almost perfect, and for Fleiss, a score $>0.75$ is excellent.(61) 
Manuscript_OPQOL-35-fr_for BMC Springer Nature_20.10.21

212

213

214

215

216

217

218

219

220

221

222

223

224

225

226

227

228 Construct validity

229

230

231

232

233

55 years

235 were extracted and identified using a minimal eigenvalue of 1 as the factor criterion. The eight 
Manuscript_OPQOL-35-fr_for BMC Springer Nature_20.10.21

236 factors explained $58 \%$ of the variance observed. Scree plots of OPQOL-35-SF test and retest

237 show an ideal number of eight factors (Figure 1a and 1b). This is more explicit in the test than

238 in the retest.

239 Title: Figure 1: Scree plot of eigenvalues from the exploratory factor analysis.

240 Legend: 1a: OPQOL-35-SF test; 1b: OPQOL-35-SF retest

241

PCA and Varimax rotation for OPQOL-35-SF test and retest (Additional material II and III)

present the repartition of the items with a significative weight $(<0.30)$ in eight factors.

Component 1 explained the largest explained proportion of the variance for the test $(0.21)$

245 and component 1 and 8 for the retest (0.19). In the Swiss French version of the questionnaire,

246 the distribution of items in the dimensions (Figure 2) differs from the original English version

247 of Bowling.(21) The dimension "Life overall" disappears and its four items (Q1-Q4) are

248 integrated into the dimension "Psychological and emotional well-being" with items Q26-Q28.

249 Item Q19 "The cost of the things compared to my pension/income restricts my life" joins the

250 dimension "Financial circumstances" with items Q30-Q33. A new dimension, entitled "Physical

251 condition" appears. It includes three items (Q5-Q7) from the original "Health" dimension,

252 three items (Q14-Q16) from the original "Social relationships/leisure and social activities"

253 dimension, and three items (Q17, Q18 and Q20) from the original "Independence, control over

254 life, freedom" dimension. The original dimension "Social relations/leisure and social activities"

255 is divided into two new separate dimensions: a dimension "Social relationship" which includes

256 items Q10, Q12 and Q21 and a dimension "Family context" which includes items Q9, Q11 and

257 Q13. Item Q22 "I feel safe where I live" disappears from the dimension "Home and 258 neighborhood". The dimension "Religion/culture" stay unchanged. Finally, three items do not 259 fit any of the identified dimensions: Q8 "I am healthy enough to get out and about", Q22 "I 
Manuscript_OPQOL-35-fr_for BMC Springer Nature_20.10.21

260

261

262

263

264

265

266

267

268

269

270

271

272

273

274

275

276

277

278

279 Title: Table 3: Correlations between total scores of QoL questionnaires (Spearman's rho)

feel safe where I live" and Q29 "If my health limits social/leisure activities, then I will compensate and find something else I can do".

Title: Figure 2: Factors' structure of the OPQOL derived form PCA

Table 2 presents the scores of the different questionnaires measuring the quality of life, in original scoring and in transformed values (TV) to be compared to OPQOL-35. The average scores of the questionnaires, scaled to OPQOL-35, ranged from $142.2+/-17.2$ for CASP-12 to 155.4 +/- 19.6 for EQ-5D-5L. The maximum score was reached in all the questionnaires except in the WHOQOL-OLD (118 out of 120).

Title: Table 2: Scores of QoL questionnaires

Legend: $n=$ number of participants; $S D=$ standard deviation; $T V=$ transformed values

\section{Convergent validity}

Table 3 shows that OPQOL-35-SF (test), EQ-5D-5L, WHOQOL-OLD, CASP-12, VAS QoL and VAS health total score all correlated lowly to moderately with each other $(r=0.384-0.663$; all $\mathrm{P}<.001) .(71)$

Legend: OPQOL-35-SF: Older People's Quality of Live Questionnaire Swiss French; VAS QoL: Visual Analogue Scale for Quality of Life; WHOQOL-OLD: World Health Organization Quality of Life in older people questionnaire; CASP-12: Control, Autonomy, Self-realization, Pleasure in 12 
Manuscript_OPQOL-35-fr_for BMC Springer Nature_20.10.21

283

284

285

286

287

288

289

290

291

292

293

294

295

296

297

298

299

300

301

302

303

304

305

306

questions; EQ-5D-5L: EuroQol-5-dimensions-5- levels; VAS health: Visual Analogue Scale for health, ${ }^{* *} p<.001$

Internal consistency

Cronbach's alpha coefficient for the total scale was 0.875 for the test and 0.902 for the retest. This shows a good internal consistency (45) and could mean that the items evaluate the same construct (72).

\section{Test-retest reliability}

262 older people completed within a time interval from 6 to 23 days the OPQOL-35-SF a second time. The mean score of the total scale for the first and the second test was 147.91 (SD 13.43) and 146.03 (SD 14.28), respectively. $I C C_{2.1}$ for the total sample ( $N=262$ ) was 0.83 (Cl 0.78-0.87), and for the sample that didn't reported events that have strongly influenced their quality of life between the first and the second meeting $(\mathrm{N}=238)$ was $0.83(\mathrm{Cl} 0.77-0.87)$.

These results show a good reliability. $(45,61)$ The ICC 2.1 of the subscales ranged between 0.58 to 0.84 for the older people without life changes, and between 0.59 to 0.82 for those that reported events having influenced their quality of life (Table 4).

Title: Table 4: OPQOL-35-SF Subscales test-retest reliability (ICC2.1)

Legend: ICC: Intraclass Correlation Coefficient; Cl: Confidence Interval

Agreement between test and retest was between $81.6 \%$ and $92.6 \%$ for the total sample and between $81.6 \%$ and $93.3 \%$ for the reduced sample (sample without extra events between test and retest). Weighted Cohen's kappa coefficients were between 0.25 and 0.7 in the total 
Manuscript_OPQOL-35-fr_for BMC Springer Nature_20.10.21

307 308 309

310 (Additional material IV).

311

\section{Discussion}

312 The aim of this study was to evaluate the psychometric properties of the Swiss French version 313 of OPQOL-35 in older people in the French speaking part of Switzerland. Political leaders as

314 well as social and health professionals need effective and validated tools to assess the quality 315 of life in older people. $(73,74)$ The results of this study demonstrate the good to very good 316 psychometric quality of the Swiss French version of the OPQOL-35 questionnaire. It also showed the complexity of the repartition of the quality of life-items in pre-defined categories. evaluating the psychometric properties in Czech (24), in Persian (23) and in Chinese (25). However, this sample is sufficient to meet the requirements and recommendations to conduct a factor analysis.(42)

EFA extracted and identified eight factors using a minimal eigenvalue of 1 as the factor

325 criterion and explained $58 \%$ of the variance observed. As the original version of Bowling, the Persian version and the Chinese version, the Swiss French version of OPQOL-35 has eight

327 dimensions, unlike the Czech version, which has seven. Based on cross-cultural aspects that 328 are reflected with the items, some dimensions of the original version have been renamed, 
Manuscript_OPQOL-35-fr_for BMC Springer Nature_20.10.21

329

330

331

333

334

335

some have fewer or more items, some dimensions have been integrated into others, and new dimensions have been created in the translated versions.

Bowling's "Life overall" dimension is still present in the Iranian version, but it is completed by two items "I take life as it comes and make the best of things" and "I feel lucky compared to most people" from the original "Psychological and emotional well-being" dimension. In the Swiss French version, the dimension "Life overall" disappears and its four items are integrated into the dimension "Psychological and emotional well-being".

The Czechs created a new dimension entitled "Positive Approach", which includes the items "I take life as it comes and try to make the best of it", "I feel happy compared to most people" and "I tend to look on the bright side of the life".

The "Health" dimension of the original version also disappeared in the Swiss French version. Three of its items integrate a new dimension "Physical condition" which also includes three items from the original dimension "Social relationship/leisure and social activities": "I have social or leisure activities/hobbies that I enjoy doing", "I try to stay involved with things" and "I do paid or unpaid work or activities that gives me a role in life". Similarly, three items from the original "Independence, control over life, freedom" dimension, namely "I am healthy enough to have my own independence", "I can please myself what I do" and "I have a lot of control over the important things in my life" are incorporated into the "Physical condition" dimension. In the Chinese version, Chen et al. (25) created a new dimension entitled "Health and Independence". It seems that, for the Swiss French population 65 years old and over, the aspects of physical condition, or health, are closely related to independence, as they are for the Chinese population. This is similar to the Czech population, as, in their version, Mares et al. (24) created a dimension entitled "Health, independence, active life" which groups some items included in the "Physical condition" dimension of the Swiss French version. 
Manuscript_OPQOL-35-fr_for BMC Springer Nature_20.10.21

353

354 The original version of Bowling has a dimension entitled "Social Relationships/Leisure and

355 Social Activities". This dimension has been modified in all translated versions of the OPQOL-

35635 , both in its title and in the items that are attached to it. The Czech version has divided the

357 items of this dimension into two new dimensions, a "Family and Safe Environment" dimension

358 and a "Loneliness" dimension. In the Swiss French version, the items of the original Bowling

359 dimension are divided into a dimension "Social Relations" and a new dimension entitled

360 "Family Context" which includes the three items "My family, friends or neighbors will help me

361 if necessary", "I have someone who gives me love and affection" and "I have my children

362 around which is important". The notion of "Family" appears explicitly in the Czech version

363 (Family and Safe Environment) and in the Swiss French version (Family context) while in the

364 English, Iranian and Chinese versions, the items referring to it are distributed in different

365 dimensions. In the Persian version, the item "My family, friends or neighborhood will help me

366 if necessary" is not included in any of the questionnaire dimensions. The fact that the Chinese

367 sample consisted exclusively of older people living alone could explain why the notion of

368 "Family" was not highlighted in the Chinese version of OPQOL.

369 The three items "I am healthy enough to get out and about", "I feel safe where I live" and "If

370 my health limits social/leisure activities, then I will compensate and find something else I can

371 do", couldn't be attributed in any identified dimensions in the Swiss French OPQOL-35.

372 Similarly, in the Persian version, Nikkhah et al. (23) were unable to include four items in the

373 identified dimensions, namely "My family, friends or neighbors would help me if needed", "I

374 can please myself what I do", "The cost of things compared to my pension/income restricts my

375 life", and "I cannot afford to do things I would enjoy". 
Manuscript_OPQOL-35-fr_for BMC Springer Nature_20.10.21

377

378

OPQOL-35-SF correlated lowly with EQ-5D-5L $(r=0.42, P<.001)$ and its VAS for health ( $r$ $=0.425, \mathrm{P}<.001)$, and moderately with VAS for QoL $(r=0.561, \mathrm{P}<.001)$, WHOQOL-OLD $(r=$ $0.656, P<.001)$ and CASP-12 $(r=0.663, P<.001)$. Quality of life is a multidimensional concept, so the low correlation with the EQ-5D-5L and its VAS could be explained by the fact that EQ$5 \mathrm{D}-5 \mathrm{~L}$ is health centered and do not explore any other dimensions as suggested in the literature.(75) The correlation between the Swiss French version of the OPQOL and the WHOQOL-OLD is relatively similar to that of the original version $(r=0.698)$ assessed in a population of English origin (ONS Omnibus) from Bowling.(21) The correlation between the Swiss French version of the OPQOL and the CASP-12 is slightly lower than the one demonstrated by Prof. Bowling in her study with the CASP-19 $(r=0.732)$. Whatsoever, the overall OPQOL score was statistically significant in correlation with validated questionnaires measuring quality of life. This supports the convergent validity of the Swiss French OPQOL.

Cronbach's alpha's coefficient for the total scale was 0.875 for the test and 0.902 for the retest. That shows a good internal consistency as to the original English version (0.876 in the ONS Omnibus and 0.901 in the Follow-up).(21) The internationally used OPQOL questionnaire has also demonstrated very good internal consistency: 0.78 in Italy(12), 0.81 in Ghana(76), 0.834 in Sri Lanka(77), 0.90 in China(25) and 0.92 in Iran(23). Considering the literature on the internal reliability of a questionnaire, the Swiss French version has a very acceptable reliability, neither too low nor too high. $(45,61,65)$

The $\mathrm{ICC}_{2.1}$ of the Swiss French OPQOL total score indicates a good test-retest reliability for a use for research purposes with values over 0.75 (total sample : $0.83, \mathrm{Cl} 0.78-0.87$; reduced sample : $0.83, \mathrm{Cl} 0.77-0.87$ (68). Because $\mathrm{ICC}_{2.1}$ is not over 0.9, it cannot be used 
Manuscript_OPQOL-35-fr_for BMC Springer Nature_20.10.21

401 individually.(78) The results of the Swiss French OPQOL are slightly lower than those obtained 402 in the Chinese (ICC 0.87) and the Persian (ICC 0.92) versions. The test-retest reliability of the 403 original English version showed Spearman's rho between 0.403 and 0.782 . Subscales' test404 retest reliability of the Swiss French OPQOL can be compared to the results of the Chinese and 405 Persian version. In the Swiss French version, two subscales show an $\mathrm{ICC}_{2.1}$ between 0.75 and 0.9 and six an ICC 2.1 between 0.5 and 0.75 ; in the Chinese version, four subscales had an ICC between 0.75 and 0.9 and four an ICC between 0.5 and 0.75 . However, the Persian version 408 showed better results with four subscales having an ICC $>0.9$, and four subscales with an ICC between 0.75 and 0.9 . The difference in these results could be explained by the difference in the length of time between filling out the questionnaires, 1 to 3 weeks in the Swiss French version, 4 weeks in the English version and 2 weeks in the Chinese and Persian version. The time between the administration of two questionnaires should be long enough to prevent subjects from remembering what they had written, but short enough to prevent a change in 414 the situation.(45) It seems that with older people, a short duration would be more appropriate.(21) The statistical methods used in these studies are also different: $I^{C C} C_{2.1}$ for the

416 Swiss French version, Spearman's rho for the English version and ICC for the Chinese and 417 Persian versions. It is possible that $\mathrm{ICC}_{2.1}$ might show smaller reliability than ICC.(68) For a 418 positive rating for reliability, weighted Kappa should be at least 0.70 (45). Following the ratings 419 of Landis and Koch(79), PABAK results between 0.80 to 1.00 means a "near-perfect agreement"; between 0.60 to 0.79 a "substantial agreement" and between 0.40 to 0.59 a

421 "moderate agreement". In the Swiss French version of OPQOL, 17 items reach a "near-perfect 422 agreement", and 18 items can be interpreted as "substantial agreement". Six items have a 423 PABAK <0.70: Q6 "I look forward to things", Q12 "I'd like more people to enjoy life with", Q16 424 "I do paid or unpaid work or activities that give me a role in life", Q19 "The cost of the things 
Manuscript_OPQOL-35-fr_for BMC Springer Nature_20.10.21

425

426

427

428

429

430

431

432

433

434

435

436

437

438

439

440

441

compared to my pension/income restricts my life", Q21 "I have responsibilities to others that restrict my social or leisure activities" and Q33 "I cannot afford to do things I would enjoy". This may be explained by the reactions of the participants. Q6 was not easily understood, the participants did not know if the item was for the present moment or in general. Participants took long time to answer Q12 because coding is reversed. Q19 and Q21 often needed clarifications. Q33, at the end of the questionnaire, follows a similar item but expressed in positive terms. Participants took more time, certainly because of the loss of the concentration. The original version of OPQOL contains voluntarily eight items with reversed scoring, to avoid automatisms. (80) The relevance of reversal coding is discussed. $(81,82)$ In their translation of the questionnaire, the Czechs decided to invert the rating in order to respond to their local and socio-cultural practice, i.e. the "best rating" is 1 and the "worst rating" is 5.(24)

For this study, SC and CM were trained to conduct "one-to-one" and "in-group" interviews. This permitted to informally record the participants' experiences when filling out the questionnaires. Some of them would have liked "memory" to be the subject of an item. Memory loss is a concern for older adults. For many of them, religion and culture are two themes to be differentiated in the items. Most participants wished they could have answered "yes" or "no." The choice of 5 answers offered by the Likert scale was not easy to integrate. Perhaps a 3-level scale should be considered for the elderly population. In addition, some of them would have liked to complete their answers with qualitative information.

The assessment of the quality of life of our seniors could complete their evaluation during physiotherapy care, either in a practice or at their home. Although the ICC test-retest reliability of the Swiss French version of the OPQOL-35 is not above 0.90 , this tool could inspire 
Manuscript_OPQOL-35-fr_for BMC Springer Nature_20.10.21

449 physiotherapists to learn about the quality of life of their older patients. The bio-psycho-social 450 care would be even more complete.

451

452 It would be interesting to continue this study by recruiting 200 additional subjects to perform 453 a confirmatory factor analysis. The authors of this study translated and assessed the 454 psychometric properties of the Swiss French version of the OPQOL-35 for Switzerland, which 455 represents $25 \%$ of the Swiss population. Switzerland has four national languages and German 456 is spoken by over $64 \%$ of the population. To our knowledge, the OPQOL-35 has not been 457 translated or validated in German. This could be the subject of future research.

458

459

460 List of abbreviation:

461 CASP: Control, Autonomy, Self-realization and Pleasure

462 EFA: Explanatory Factor Analysis

463 EQ: EuroQol

464 ICC2.1: Intra-class Correlation Coefficient, two-way random effects, absolute agreement, 465 single rater

466 KMO: Kaiser-Meyer-Olkin measure of sampling adequacy

467 OPQOL: Older People's Quality Of Life questionnaire

468 PABAK: Prevalence-Adjusted Bias-Adjusted Kappa

469 PCA: Principal Component Analysis

470 QoL: Quality of Life

471 REDCap: Research Electronic Data Capture 
Manuscript_OPQOL-35-fr_for BMC Springer Nature_20.10.21

472 VAS: Visual Analogue Scale

473 WHO: World Health Organization

474 Declarations

475 Ethics approval and consent to participate

476 This study was approved by the Swissethics committee (project 38/14). All participants

477 received an information letter and signed an informed consent.

478 Consent for publication

$479 \quad$ Not applicable

480 Availability of data and materials

481 The datasets used and/or analyzed during the current study are available from the

482 corresponding author on reasonable request.

483 Competing interests

484 The authors declare that they have no competing interests.

485 Funding

$486 \quad$ Not applicable

487 Author's contributions

488 AGMH: conception and design, interpretation, drafting the article, critical revision, and final 489 approval

$490 \mathrm{CM}$ : collection and interpretation of the data and final approval

491 RH: statistical analysis and final approval

492 SC: collection and interpretation of the data, statistical analysis, critical revision of the article 493 and final approval 
Manuscript_OPQOL-35-fr_for BMC Springer Nature_20.10.21

494

495

496 Additional material

497

498 Additional material I:

499 File name: Additional material I.pdf

500 Title: Score's conversions

501 Description of data: Table displaying the equation of the conversion of the score of the

502 questionnaires to meet the range of scores of the OPQOL.

503

504

505 Additional material II:

506 File name: Additional material II.pdf

507 Title: Principal Component Analysis (test)

508 Description of data: Table displaying the detailed results of the PCA for the test

509

510

511 Additional material III:

512 File name: Additional material III.pdf

513 Title: Principal Component Analysis (retest)

514 Description of data: Table displaying the detailed results of the PCA for the retest 515

516 
Manuscript_OPQOL-35-fr_for BMC Springer Nature_20.10.21

517 Additional material IV:

518 File name: Additional material IV.pdf

519 Title: Cohen's kappa and PABAK

520 Description of data: Table displaying the detailed results of the Cohen's kappa and PABAK

521 separated for the total sample and the reduced sample 
Manuscript_OPQOL-35-fr_for BMC Springer Nature_20.10.21

\section{References}

2 1. Organisation WH. Decade of Helthy Ageing 2020-2030 [cited 2020. Available from:

3 https://www.who.int/ageing/decade-of-healthy-ageing.

42 2. Organisation WH. Ageing and health [cited 2020. Available from:

5 https://www.who.int/news-room/fact-sheets/detail/ageing-and-health.

6 3. Giacalone D, Wendin K, Kremer S, Frøst MB, Bredie WL, Olsson V, et al. Health and

7 quality of life in an aging population-Food and beyondq. 2014.

84 Holliday R. Aging and the decline in health. Health. 2010;2(6):615-9.

9 5. Tinetti ME, Fried TR, Boyd CM. Designing health care for the most common chronic

10 condition-multimorbidity. Jama. 2012;307(23):2493-4.

11 6. Smith SM, Soubhi H, Fortin M, Hudon C, O'Dowd T. Managing patients with

12 multimorbidity: systematic review of interventions in primary care and community settings.

13 Bmj. 2012;345:e5205.

14 7. Ilinca S, Leichsenring K, Rodrigues R. From care in homes to care at home: European 15 experiences with (de) institutionalisation in long-term care.

16 8. Van Leeuwen KM, Van Loon MS, Van Nes FA, Bosmans JE, De Vet HC, Ket JC, et al.

17 What does quality of life mean to older adults? A thematic synthesis. PloS one.

$18 \quad$ 2019;14(3):e0213263.

19 9. Kröger T, Bagnato A. Care for older people in early twenty-first-century Europe:

20 dimensions and directions of change. Social services disrupted: Edward Elgar Publishing;

212017. 
Manuscript_OPQOL-35-fr_for BMC Springer Nature_20.10.21

10. OFS. Santé des personnes âgées [cited 2020. Available from:

https://www.bfs.admin.ch/bfs/fr/home/statistiques/sante/etat-sante/personnesagees.html.

11. Borglin G, Edberg A-K, Hallberg IR. The experience of quality of life among older people. Journal of aging studies. 2005;19(2):201-20.

12. Bilotta C, Bowling A, Nicolini P, Casè A, Pina G, Rossi SV, et al. Older People's Quality of Life (OPQOL) scores and adverse health outcomes at a one-year follow-up. A prospective cohort study on older outpatients living in the community in Italy. Health and quality of life outcomes. 2011;9(1):72.

13. Lawton M, Birren J, Lubben J, Rowe J, Deutchman D. The concept and measurement of quality of life in the frail elderly. The concept of Measurement of Quality of Life in the Frail Elderly San Diego: Academic Press, Inc. 1991.

14. CURAVIVA.CH. Conception de la qualité de vie. suisses Adheis; 2014.

15. Halvorsrud L, Kalfoss M. The conceptualization and measurement of quality of life in older adults: a review of empirical studies published during 1994-2006. European journal of ageing. 2007;4(4):229-46.

16. Power M, Quinn K, Schmidt S. Development of the WHOQOL-old module. Quality of life research. 2005;14(10):2197-214.

17. Hyde $M$, Wiggins RD, Higgs $P$, Blane DB. A measure of quality of life in early old age: the theory, development and properties of a needs satisfaction model (CASP-19). Aging \& mental health. 2003;7(3):186-94.

18. Borrat-Besson C, Ryser V-A, Gonçalves J. An evaluation of the CASP-12 scale used in the Survey of Health, Ageing and Retirement in Europe (SHARE) to measure Quality of Life among people aged 50. Lausanne: FORS. 2015. 
Manuscript_OPQOL-35-fr_for BMC Springer Nature_20.10.21

19. Caballero FF, Miret M, Power M, Chatterji S, Tobiasz-Adamczyk B, Koskinen S, et al. Validation of an instrument to evaluate quality of life in the aging population: WHOQOLAGE. Health and quality of life outcomes. 2013;11(1):177.

20. Schmidt S, Mühlan H, Power M. The EUROHIS-QOL 8-item index: psychometric results of a cross-cultural field study. The European Journal of Public Health. 2006;16(4):420-8.

21. Bowling A. The psychometric properties of the older people's quality of life questionnaire, compared with the CASP-19 and the WHOQOL-OLD. Current gerontology and geriatrics research. 2009;2009.

22. Bowling A, Hankins M, Windle G, Bilotta C, Grant R. A short measure of quality of life in older age: The performance of the brief Older People's Quality of Life questionnaire (OPQOL-brief). Archives of gerontology and geriatrics. 2013;56(1):181-7.

\section{Nikkhah M, Heravi-Karimooi M, Montazeri A, Rejeh N, Nia HS. Psychometric} properties the Iranian version of older People's quality of life questionnaire (OPQOL). Health and quality of life outcomes. 2018;16(1):174.

24. Mares J, Cigler H, Vachkova E. Czech version of OPQOL-35 questionnaire: the evaluation of the psychometric properties. Health and quality of life outcomes. 2016;14(1):93.

25. Chen $\mathrm{Y}$, Hicks A, While AE. Validity and reliability of the modified $\mathrm{C}$ hinese version of the $O$ Ider $P$ eople's $Q$ uality of $L$ ife $Q$ uestionnaire (OPQOL) in older people living alone in $C$ hina. International journal of older people nursing. 2014;9(4):306-16.

26. GUMIKIRIZA-ONORIA MJL, FELLOW N. Cultural adaptation of the Older People's Quality of life Questionnaire (OPQOL) to Uganda's elderly population.

27. Dhamo E, Koçollari N. Older people quality of life evaluation. Mediterranean Journal of Social Sciences. 2014;5(13):385. 
Manuscript_OPQOL-35-fr_for BMC Springer Nature_20.10.21

28. Rajput M, Bhatt S. Comparing the effect of two different dual task training conditions on balance and gait in elderly. J Med Sci Clin Res. 2014;2:2510-9.

29. Siriwardhana DD, Weerasinghe MC, Rait G, Scholes S, Walters KR. The association between frailty and quality of life among rural community-dwelling older adults in Kegalle district of Sri Lanka: a cross-sectional study. Quality of Life Research. 2019;28(8):2057-68. 30. Siddiqui AT, Hasan M, Abbas K, Tariq SM, Haider SA. Health related quality of life of home dwelling vs. nursing facility dwelling elderly-A cross-sectional study from Karachi, Pakistan. JPMA The Journal of the Pakistan Medical Association. 2019;69(6):892-5.

31. Johani S, Alavi K, Mohamad MS. Perbandingan Tahap Kualiti Hidup Bagi Warga Emas Yang Mendapatkan Perkhidmatan Di Pusat Aktiviti Warga Emas (PAWE) Di Kawasan Bandar Dan Luar Bandar (Comparison of Quality of Life Level among Elderly at Elderly Activity Center in Urban and Rural Areas). Jurnal Psikologi Malaysia. 2018;32(3).

32. Cahyaningtias RN. Hubungan Kemungkinan Kejadian Depresi dengan Kualitas Hidup Pada Lanjut Usia Dengan Pendekatan: Biopsikososisospiritual di Puskesmas: Ciputat, Ciputat Timur, Dan Pondok Ranji Tahun 2018. 2019: UIN Syarif Hidayatullah Jakarta-FK.

33. Caliskan H, Aycicek GS, Ozsurekci C, Dogrul RT, Balci C, Sumer F, et al. Turkish validation of a new scale from older people's perspectives: Older people's quality of life-brief (OPQOL-brief). Archives of gerontology and geriatrics. 2019;83:91-5.

34. Feizi A, Heidari Z. Persian version of the brief Older People's Quality of Life questionnaire (OPQOL-brief): the evaluation of the psychometric properties. Health and Quality of Life Outcomes. 2020;18(1):1-11.

35. Haugan G, Drageset J, André B, Kukulu K, Mugisha J, Utvær BKS. Assessing quality of life in older adults: psychometric properties of the OPQoL-brief questionnaire in a nursing home population. Health and Quality of Life Outcomes. 2020;18(1):1. 
Manuscript_OPQOL-35-fr_for BMC Springer Nature_20.10.21

94

95

96

97

98

99

100

101

102

103

104

105

106

107

108

109

110

111

112

113

114

115

116

36. francophonie Oidl. La langue française dans le monde 2018. 2019 Mars 2019.

37. Bowling A, Gabriel Z. Lay theories of quality of life in older age. Ageing Soc.

2007;27(6):827-48.

38. Bowling A, Stenner P. Which measure of quality of life performs best in older age? A

comparison of the OPQOL, CASP-19 and WHOQOL-OLD. Journal of Epidemiology \&

Community Health. 2011;65(3):273-80.

39. Beaton DE, Bombardier C, Guillemin F, Ferraz MB. Guidelines for the process of crosscultural adaptation of self-report measures. Spine. 2000;25(24):3186-91.

40. Bütikofer A, Rausis L. Validité et fiabilité de la traduction transculturelle suisse-

romande du Questionnaire « Older People's Quality of Life Questionnaire »: Haute Ecole de Santé HES-SO Valais-Wallis; 2017.

41. Williams B, Onsman A, Brown T. Exploratory factor analysis: A five-step guide for novices. Australasian journal of paramedicine. 2010;8(3).

42. Roussel P. Méthodes de développement d'échelles pour questionnaires d'enquête. Management des Ressources Humaines: Méthodes de recherche en sciences humaines et sociales. 2005:245-76.

43. Hair JF, Black WC, Babin BJ, Anderson RE, Tatham RL. Multivariate data analysis:

Prentice hall Upper Saddle River, NJ; 1998.

44. Munro BH. Statistical methods for health care research: lippincott williams \& wilkins; 2005.

45. Terwee CB, Bot SD, de Boer MR, van der Windt DA, Knol DL, Dekker J, et al. Quality criteria were proposed for measurement properties of health status questionnaires. Journal of clinical epidemiology. 2007;60(1):34-42. 
Manuscript_OPQOL-35-fr_for BMC Springer Nature_20.10.21

117

118

119

120

121

122

123

124

125

126

127

128

129

130

131

132

133

134

135

136

137

138

139

140

46. Leplege A, Perret-Guillaume C, Ecosse E, Hervy M, Ankri J, von Steinbüchel N. A new instrument to measure quality of life in older people: The French version of the WHOQOLOLD. La Revue de Medecine Interne. 2012;34(2):78-84.

47. Perneger TV, Combescure C, Courvoisier DS. General population reference values for the French version of the EuroQol EQ-5D health utility instrument. Value in health. 2010;13(5):631-5.

48. Hawker GA, Mian S, Kendzerska T, French M. Measures of Adult Pain: Visual Analog Scale for Pain (VAS Pain), Numeric Rating Scale for Pain (NRS Pain), McGill Pain Questionnaire (MPQ), Short-Form McGill Pain Questionnaire (SF-MPQ), Chronic Pain Grade Scale (CPGS), Short Form-36 Bodily Pain Scale (SF-36 BPS), and Measure of Intermittent and Constant Osteoarthritis Pain (ICOAP). Arthritis care \& research. 2011;63:S240-S52.

49. Brokelman RB, Haverkamp D, van Loon C, Hol A, van Kampen A, Veth R. The validation of the visual analogue scale for patient satisfaction after total hip arthroplasty. European Orthopaedics and Traumatology. 2012;3(2):101.

50. Williams VS, Morlock RJ, Feltner D. Psychometric evaluation of a visual analog scale for the assessment of anxiety. Health and quality of life outcomes. 2010;8(1):1-8.

51. Gudex $C$, Dolan $P$, Kind $P$, Williams A. Health state valuations from the general public using the visual analogue scale. Quality of Life Research. 1996;5(6):521-31.

52. Eboli G. Le Guichet du Savoir 2008 [Available from:

https://www.guichetdusavoir.org/viewtopic.php?t=30050.

53. de Boer A, van Lanschot J, Stalmeier P, van Sandick J, Hulscher J, de Haes J, et al. Is a Single-Item Visual Analogue Scale as Valid, Reliable and Responsive as Multi-Item Scales in Measuring Quality of Life? Quality of life research: an international journal of quality of life aspects of treatment, care and rehabilitation. 2004;13(2):311-20. 
Manuscript_OPQOL-35-fr_for BMC Springer Nature_20.10.21

141 54. Buber I, Prskawetz A, Engelhardt H, Schwarz F, Winter-Ebmer R. Survey of Health,

142 Ageing and Retirement in Europe. SHARE First Results for Austria Forschungsbericht.

$1432006 ; 31$.

144 55. Wiggins RD, Netuveli G, Hyde M, Higgs P, Blane D. The evaluation of a self-

145 enumerated scale of quality of life (CASP-19) in the context of research on ageing: A

146 combination of exploratory and confirmatory approaches. Social Indicators Research.

$147 \quad 2008 ; 89(1): 61-77$.

148 56. Group E. EQ-5D 2017 [Available from: https://euroqol.org/eq-5d-instruments/eq-5d-

149 5l-about/.

150 57. Marx RG, Menezes A, Horovitz L, Jones EC, Warren RF. A comparison of two time

151 intervals for test-retest reliability of health status instruments. Journal of clinical

152 epidemiology. 2003;56(8):730-5.

153 58. Patridge EF, Bardyn TP. Research electronic data capture (REDCap). Journal of the

154 Medical Library Association: JMLA. 2018;106(1):142.

155 59. Baumgartner $\mathrm{H}$, Homburg C. Applications of structural equation modeling in

156 marketing and consumer research: A review. International journal of Research in Marketing.

$157 \quad 1996 ; 13(2): 139-61$.

158 60. DeVon HA, Block ME, Moyle-Wright P, Ernst DM, Hayden SJ, Lazzara DJ, et al. A

159 psychometric toolbox for testing validity and reliability. Journal of Nursing scholarship.

160 2007;39(2):155-64.

161 61. De Vet HC, Terwee CB, Mokkink LB, Knol DL. Measurement in medicine: a practical

162 guide: Cambridge University Press; 2011.

163 62. Kaiser HF. A second generation little jiffy. Psychometrika. 1970;35(4):401-15. 
Manuscript_OPQOL-35-fr_for BMC Springer Nature_20.10.21

164

165

166

167

168

169

170

171

172

173

174

175

176

177

178

179

180

181

182

183

184

185

186

187

63. Glen S. Statistics How To 2020 [Available from:

https://www.statisticshowto.com/kaiser-meyer-olkin.

64. Hair J, Black W, Babin B, Anderson R. Multivariate data analysis (Pearson new internat. ed). Harlow: Pearson. 2014.

65. Touzani M, Salaani T. Le processus de validation des échelles de mesure: fiabilité et validité. Marketing. 2000;11(3):73.

66. Bowling A. Measuring the quality of later life. The New Dynamics of Ageing Volume 1. 2018;1:81.

67. McDowell I. Measuring health: a guide to rating scales and questionnaires: Oxford University Press, USA; 2006.

68. Koo TK, Li MY. A Guideline of Selecting and Reporting Intraclass Correlation Coefficients for Reliability Research. J Chiropr Med. 2016;15(2):155-63.

69. Sim J, Wright CC. The kappa statistic in reliability studies: use, interpretation, and sample size requirements. Physical therapy. 2005;85(3):257-68.

70. Byrt T, Bishop J, Carlin JB. Bias, prevalence and kappa. Journal of clinical epidemiology. 1993;46(5):423-9.

71. Mukaka MM. A guide to appropriate use of correlation coefficient in medical research. Malawi medical journal. 2012;24(3):69-71.

72. Henson RK. Understanding internal consistency reliability estimates: A conceptual primer on coefficient alpha. Measurement and evaluation in counseling and development. 2001;34(3):177-89.

73. Zimmermann-Sloutskis D, Gruet F, Zimmermann E. Comparaison de la qualité de vie des personnes âgées vivant à domicile ou en institution: Observatoire suisse de la santé (Obsan); 2012. 
Manuscript_OPQOL-35-fr_for BMC Springer Nature_20.10.21

188

189

190

191

192

193

1942014.

195 77. Rathnayake S, Siop S. Quality of Life and Its Determinants among Older People Living 196 in the Rural Community in Sri Lanka. Indian Journal of Gerontology. 2015;29(2).

197 78. Nunnally J, Bernstein I. Psychometric theory. New York. 1994.

198 79. Landis JR, Koch GG. The measurement of observer agreement for categorical data.

199 biometrics. 1977:159-74.

200 80. Ashton MMC. Psychologie de la personnalité et des différences individuelles: De

201 Boeck Superieur; 2014.

202 81. Suárez Álvarez J, Pedrosa I, Lozano LM, García Cueto E, Cuesta Izquierdo M, Muñiz

203 Fernández J. Using reversed items in Likert scales: A questionable practice. Psicothema, 30.

2042018.

205 82. Sonderen Ev, Sanderman R, Coyne JC. Ineffectiveness of reverse wording of 206 questionnaire items: Let's learn from cows in the rain. PloS one. 2013;8(7):e68967. 
Figures
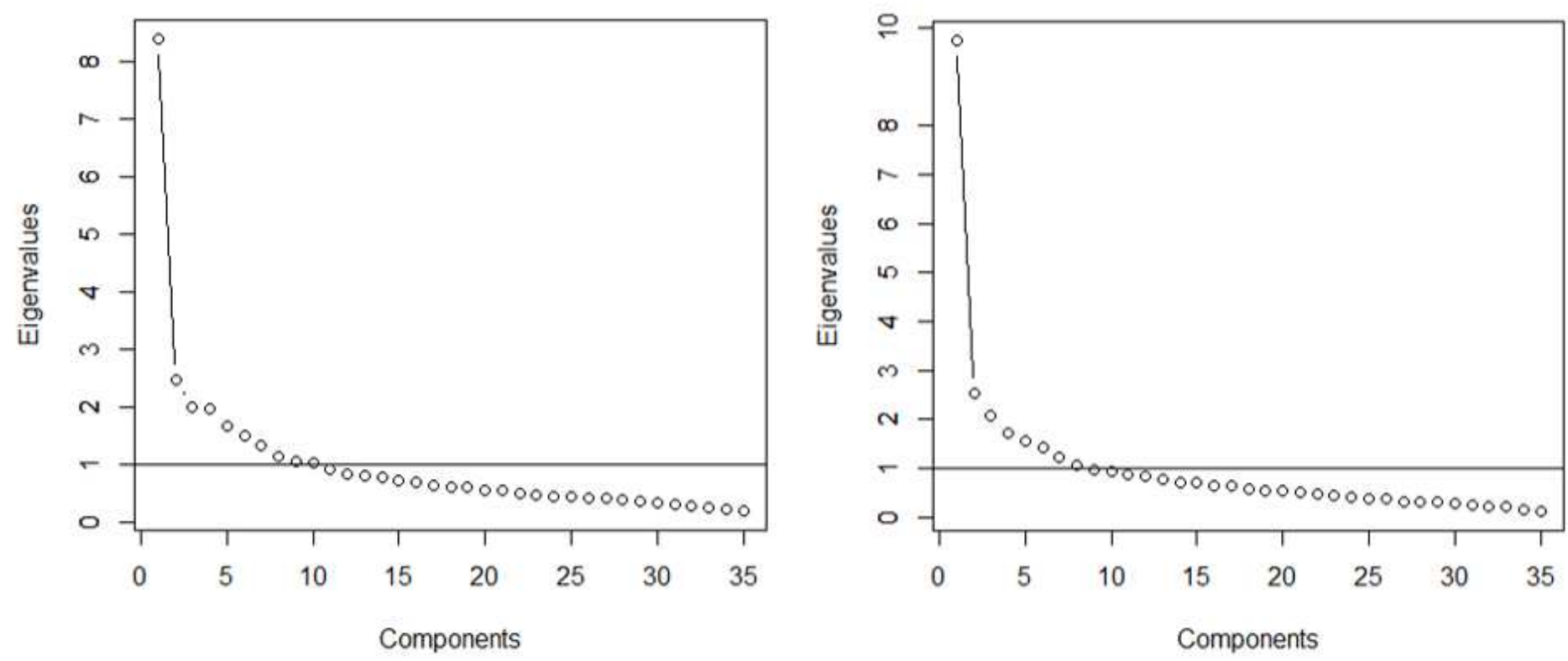

\section{Figure 1}

Scree plot of eigenvalues from the exploratory factor analysis. 1a: OPQOL-35-SF test; $1 \mathrm{~b}$ : OPQOL-35-SF retest 

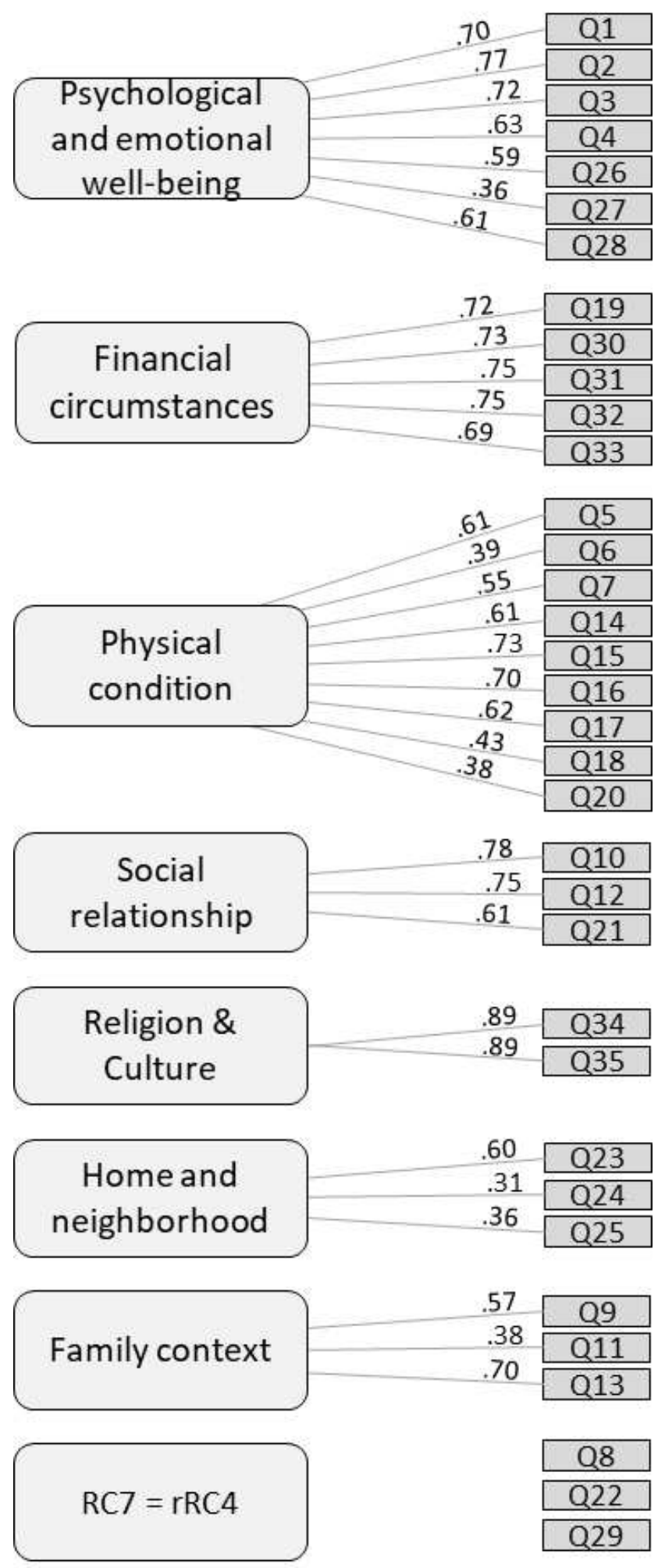

Figure 2

Factors' structure of the OPQOL derived form PCA

\section{Supplementary Files}

This is a list of supplementary files associated with this preprint. Click to download. 
- Additionalmateriall.pdf

- Additionalmaterialll.pdf

- Additionalmateriallll.pdf

- AdditionalmaterialIV.pdf 